has been increase in the number of fibre-forming granules and in the kinds and complexities of the fibrous structures they produce ${ }^{27}$. The most primitive forms have a single granule and a single fibrous structure, the flagellum. The most evolved forms have large numbers of granules forming not only flagella but also axostyles, costa, cresta, parabasal bodies, etc., of varying complexity. Replication of the basic structure, the unit granule, was followed by differentiation among its products. In the Ciliates, these granules (kinetosomes) and their fibrous products lie in rows below the body surface ${ }^{28}$. Paramecium possesses more than 3,000 such units of cortical structure. Each unit is walled off by ridges, but is open internally. Had the boundaries been completed and each unit supplied with a nucleus, Paramecium would be a metazoan. Instead, the single central nucleus became highly polyploid, the unit boundaries in the cytoplasm remained open, and replication failed to achieve metazoan multicellularity.

The principle of replication followed by differentiation is not limited to this protozoan line of evolution. On one hand, it can be discerned on the smaller levels of organization. The preservation of new gene functions arising by mutation is facilitated by duplication of chromosome segments. The enormous variation in deoxyribonucleic acid seems to be based on replications of sequences of a few purines and pyrimidines with variations in the sequence. The variation in the backbones of proteins involves comparable replications and variations in the sequence of about two dozen amino-acid units. On the other hand, a similar principle appears also on larger levels of organization. The lowest multicellular organisms simply repeat a basic cellular unit; evolution of higher forms involves variation in these replicated units. Proceeding further, groups of cells form a unit which is repeated and varied, appearing as metamerism. Similar relations appear on up to insect and human societies where individuals and groups of individuals form the units that replicate and vary. From the molecular to the social levels, the same fundamental tactic of evolution is seen : repeat, then vary.

'Kalmus, H., "Paramecium, Das Pantoffeltierchen" (G. Fischer, Jena, 193i)

'Sonneborn, T. M., "Adv. Genet.", 1, 264 (1947).

"Wichterman, R., "The Biology of Paramecium" (Blakiston, New York-Toronto, 1953).

"Beale, G. H., "The Genetics of Paramecium aurelia” (Cambridge Univ. Press, 1954).

${ }^{5}$ Sonneborn, T. M., Heredity, 4, 11 (1950).

- Preer, jun., J. R., and Stark, Pearl, Exp. Cell Res., 5, 478 (1953).

' Lederberg, J., Physiol. Rev., 32, 403 (1952).

- Preer, jun., J. R., Genetics, 33, 394 (1948).

- Dippell, Ruth V., Heredity, 4, 165 (1950).

${ }^{10}$ Hanson, E., thesis, Indiana Univ. (1954).

${ }^{11}$ Chao, P. K., Proc. U.S. Nat. Acad. Sci., 39, 103 (1953)

${ }^{12}$ Chao, P. K., Microbiol. Genetics Bull., 11, 11 (1954).

13 Siegel, R. W., Physiol. Zool., 27, 89 (1954).

14 Sonneborn, T. M., Microb. Gen. Bull., 11, 24 (1954).

${ }^{15}$ Sonneborn, T. M., Microb. Gen. Bull., 11, 25 (1954).

${ }^{16}$ Sonneborn, T. M., Caryologia, supp. vol., 307 (1954).

17 Fauré-Fremiet, E., Rev. Suisse Zool., 60, 426 (1953).

18 Levine, M., Evol., 7, 366 (1953).

19 Sonneborn, T. M., Microb. Gen. Bull., 7, 22 (1953).

${ }^{20}$ Chen, T. T., J. Morph., 79, 125 (1946).

11 Butzel, H. M., thesis, Indiana Univ. (1953).

22 Dippell, Ruth V., Caryologia (in the press).

2s Jennings, H. S., J. Exp. Zool., 97, 165 (1944)

24 Sonneborn, T. M., J. Prot., 1, 38 (1954).

${ }^{25}$ Jennings, H. S., Biol. Bull., 86, 131 (1944).

${ }^{28}$ Nanney, D. L., Proc. U.S. Nat. Acad. Sci., 39, 113 (1953)

27 Kirby, H., Rev. Soc. Mex. Hist. Nat., 10, 57 (1949).

Lwoff, A., "Problems of Morphogenesis in Ciliates" (John Wiley and Co., New York, 1950).

\section{THE NATIONAL PHYSICAL LABORATORY OPEN DAY}

$T$ HE annual open day of the National Physical Laboratory took place on May 20. More than two hundred exhibits, nearly half of them new, were on view to two thousand two hundred guests of the Laboratory, representing industry, the universities and government departments, this record attendance being nearly twice that of last year. The General Board of the Laboratory held its annual meeting during the afternoon.

An item of topical interest was the commencement of a new research programme on helicopters. A tandem-rotor model $6 \mathrm{ft}$. long (Fig. I) is at present being studied by the Aerodynamics Division in a wind tunnel. The forward rotor of the helicopter is fixed in position while the aft rotor can be moved longitudinally or vertically and its axis tilted fore and aft. The rotors are coupled together mechanically and driven by two 3-h.p. electric motors, housed within the helicopter body, at a maximum speed of 1,800 r.p.m. producing a peripheral tip speed of $400 \mathrm{ft}$./s. corresponding to a radial acceleration of $2,340 \mathrm{~g}$. To keep the masses of the blades as low as possible, they are made of hollow magnesium alloy with leading edges of brass, so that the centre of gravity of each blade is approximately coincident with its centre of pressure, thus reducing distortion in twist. To safeguard personnel in case of blade failure, the tunnel has been reinforced with steel plate.

Many of the difficulties encountered in high-speed flight with fixed-wing aircraft are due to flowseparation from the surface of a wing either near the leading edge or at a shock wave lying farther aft. The Division is studying this phenomenon and demonstrated the detailed observation of the flow around two-dimensional aerofoils at transonic speeds. The new 36 in. $\times 14$ in. induced flow tunnel which operates up to a Mach number of $1 \cdot 8$ was shown. At present still being calibrated, this tunnel will be used for studying flow past aerofoils and the aerodynamic damping of oscillating wings. As the flow-separation parameters of aerofoils cannot, in general, be varied independently over a wide range, experiments are in progress on flow-separation induced by shock waves from flat and curved plates. This enables the conditions leading to flow-separation from unswept wings to be predicted and its effects understood. Swept-back wings present special problems, and detailed observations of flow are being made at high subsonic, transonic and supersonic speeds. Among the boundary-layer control techniques being investigated is the use of suction through a porous skin ; an example of this on display in a low-speed tunnel was a body of revolution representing a fuselage with a central section perforated to apply the suction.

The Control Mechanisms and Electronics Division displayed a magnetic storage drum, identical to that now fitted to the ACE pilot model digital computor, which embodies an improved shift system to move sixteen pairs of heads into eight positions, so providing 128 tracks each 1,024 digits long. The drum is constructed of bronze coated with a tough $0 \cdot 001-i n$. thick layer of magnetic oxide in epoxy resin. The high density of this coating results in excellent magnetic properties, so that one digit occupies only 0.012 in. square. Another device, which has been 


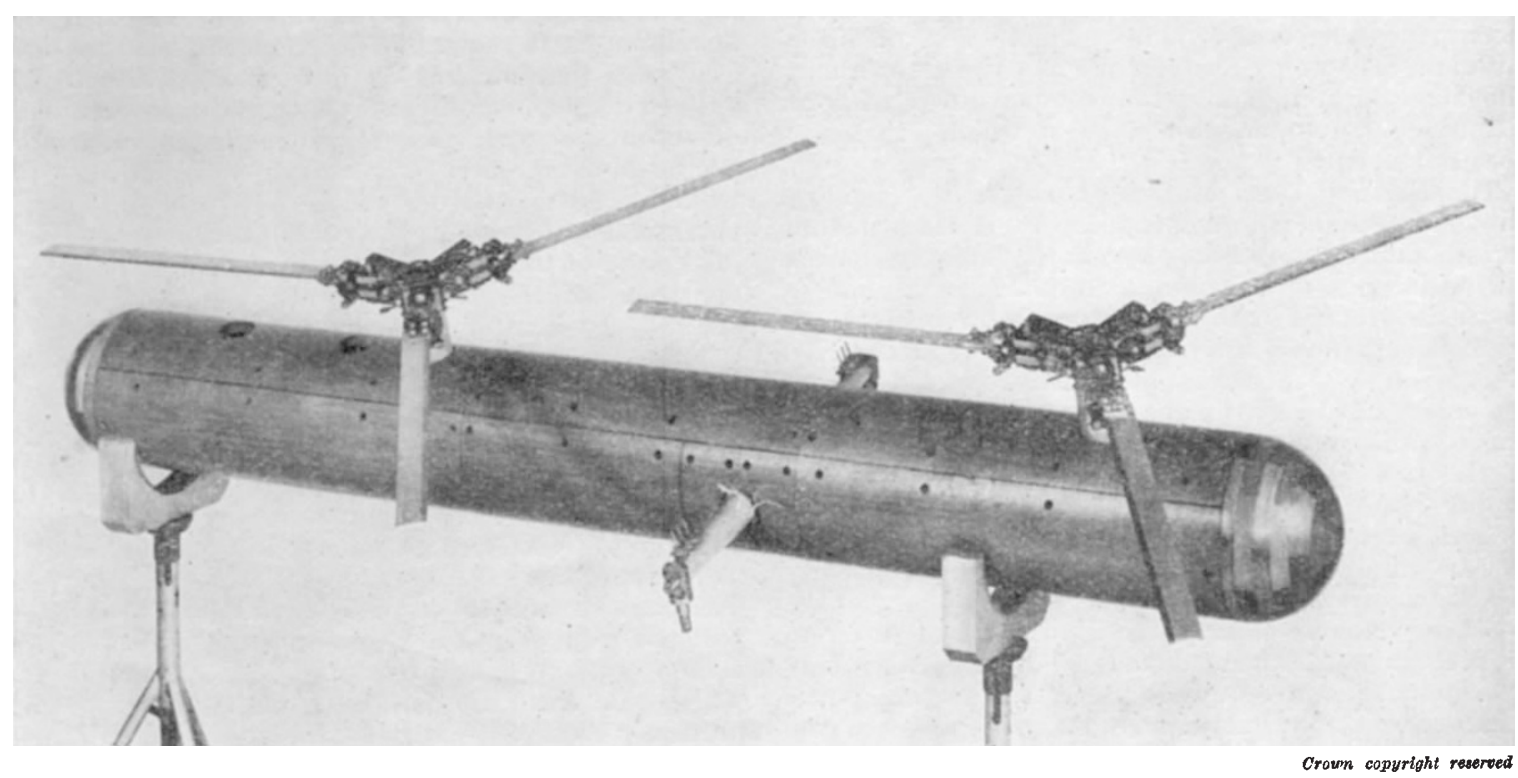

Fig. 1. Tandem-rotor model helicopter being used for wind tunnel tests

developed for the British Coal Utilization Research Association, is a data processer fitted to a commercial self-balancing recorder so that the voltage at each of sixteen inputs is recorded sequentially by means of an automatic typewriter or a card puncher. The device contains a photo-etched brass disk, the etched portions of which are filled with insulating resin in contact with brushes which energize relays in a pattern dictated by the angular position of the disk.

The N.P.L. electronic simulator has been enlarged and is now available for use by industry. Its scope has been extended by the addition of a number of non-linear units including a general function generator.

Apparatus for the detection of atomic resonance in a cæsium atomic beam was demonstrated by the Electricity Division. Based on the work of Rabi, a resonance at $9192 \cdot 632 \mathrm{Mc} / \mathrm{s}$. resulting from the interaction between nuclear and electronic spin is found by injecting a radio-frequency signal into a stream of cæsium atoms focused sharply on to a slit by two magnets. Behind the slit the beam is detected by a hot tungsten wire which boils off the cæsium as ions, producing a current which can be measured. At resonance the beam is de-focused, resulting in a fall of this ionic current. By using an exciting field normal to the beam, Doppler effect is eliminated; a high vacuum prevents broadening by collision while saturation is obviated by using each atom once only. Thus, as the $Q$ of the system is $3 \times 10^{7}$, the frequency of resonance should be determinable to better than one part in $10^{\circ}$ and will be used for calibrating quartz standards of frequency and timie.

The Light Division displayed a three-tier double trichromator consisting of three dispersive systems each similar to a van Cittert double monochromator with cancelling dispersions in the two stages. The systems are mounted vertically above each other, and a series of wedges enables the various intensities to be controlled. The trichromator is being used for a new determination of the colour-matching properties of the average eye with special attention to the differences between observations for small and large colour patches.
The Division is collaborating with the Metrology Division in experiments to determine the density of mercury to one part in $10^{6}$, an accuracy necessary to exploit fully the new primary standard barometer. Two hollow cubes with $75 \mathrm{~mm}$. sides have been built up from fused quartz plates wrung together. The precision of manufacture of these plates is such that, before wringing, each face was flat to $0 \cdot 1$ fringe, and the angles within $0 \cdot 2^{\prime \prime}$ of $90^{\circ}$. The volumes of the cubes will be known to one part in $10^{6}$. They will be filled in vacuo through a small capillary in the top plate and the mercury contents weighed to determine the density. This experiment supplements another determination based on the weighing in mercury of an equally precise solid cube of tungsten carbide of 3.5 in. face.

The Mathematics Division displayed DEUCE (digital electronic universal computing engine), an improved and engineered version of the ACE pilot model. This machine is the first of several being built by the English Electric Co. It uses tho binary scale to represent numbers by trains of pulses generated at $1 \mathrm{Mc} / \mathrm{s}$. Numerical data and instructions are injected from punched cards and the results recorded similarly, either in binary form for later computation or in decimal form for printing. It has high-speed mercury delay-line storage as well as a magnetic drum similar to that described above. The Division also demonstrated new punched-card equipment, including an electronic calculating punch which can multiply two 20-digit numbers together in a second.

The Metallurgy Division is investigating grainboundary embrittlement. While studying the properties of pure iron, it was found that slight additions of certain impurities sometimes caused extreme embrittlement. Unlike the well-known effect observed in gold containing bismuth, there is no precipitation of a separate identifiable phase in the boundaries, and the magnitude of the effect depends on the heat treatment of the alloy. In the absence of any discrete phase, there is no complete explanation of the extreme embrittlement, but it 
seems likely that some segregation of foreign atoms must occur; various techniques are being used in an attempt to detect it. The phenomenon of intergranular brittleness also occurs in copper-antimony alloys at both high and low temperatures with an intermediate temperature-range in which brittleness does not occur.

The Division has commenced a new investigation on the mechanism of fatigue. It is known that certain changes may take place in the lattice structure during fatigue, and attempts to detect such changes at an early stage in the process are now being made by focusing a fine beam of partially monochromatized $\mathrm{X}$-rays on a small area in which repeated slip is occurring. Thin specimens are used permitting the photographic observation of the low-angle scattering of the transmitted beam. Initial observations on copper have shown a very characteristic low-angle pattern produced in conditions of fatigue, and this can be interpreted in terms of changes of density occurring in the slip plane.

A mechanical fiducial indicator for fitting to proving rings has been developed by the Metrology Division. This not only facilitates the setting of the micrometer screw but also shows at a glance if the deflexion is changing and thus indicates if the load is subject to vibration or creep. Although the wavelength of light is now used for many precise length determinations, line standards and scales are still of fundamental importance, and an investigation is proceeding on their intercomparison by photographic means. A graduation line is a shallow groove, and the density of its photographic image falls off gradually as one moves across it. However, the maximum change of density is well defined and is independent of both the characteristics of the emulsion and its processing. By observing the density gradient with a microphotometer, it is hoped to compare two standards to an accuracy of a few hundred thousandths of a millimetre.

One item of considerable contemporary importance was a comparator for measuring the pitch errors of the fir-tree-root serrations of gas turbine blades. The blades are mounted in such a way that measurement of the vertical heights above a datum formed by the lowest serrations gives the spacings rapidly and with high accuracy.

To meet the requirements of organizations doing research at low temperatures, the Physics Division is arranging to make liquid helium for them in its Collins eryostat. Up to 15 litres will be supplied in double 'dewars' cooled with liquid nitrogen, and the helium gas evolved in use collected for re-liquefaction. The Division has just completed the most comprehensive series of experiments yet conducted for the determination of equal-loudness contours for the human ear. This work was carried out at the request of the British Standards Institution, and the results should form an acceptable basis for a new standard in subjective acoustics.

Recent increased demand for heat insulation at low temperatures has resulted in the development of appropriate apparatus to measure the thermal conductivities of various materials. The heat flow is from a source at room temperature to a sink cooled by liquid nitrogen or solid carbon dioxide. Samples of materials such as fine fibred glass, expanded plastic and lightweight powder have already been tested.

The Ship Division demonstrated a new apparatus which determines the rate of saturation of air from bubbles in water, information on this being required for the design of cavitation tunnels. Another new development is the use of radio-controlled models to study the manœuvring characteristics of ships. The system demonstrated operates on a carrier frequency of $465 \mathrm{Mc} / \mathrm{s}$. with nine audio channels each feeding a change-over relay. 'The relays control three starwound repeater motors which drive the rudder and two selector switches controlling the speeds and directions of the two propulsion motors. The rate of operation of the shore controls is limited to scale speeds by centrifugal governors.

Midwives may now administer trichloroethylene B.P. as an analgesic with inhalers approved by the Central Midwives' Board, which issues a certificate of approval of satisfactory apparatus valid for six months. The National Physical Laboratory has undertaken the testing of the inhalers to the specification of the Medical Research Council, and the Test House has set up a new section for this purpose. Temperature-controlled boxes each hold four inhalers, and the trichloroethylene-air mixture is drawn from them by a special pump with an adjustable rate which simulates human breathing. For the high accuracy required, a Rayleigh refractometer is used for the volumetric analysis; other tests include the measurement of resistance to airflow and mechanical inspection.

A. J. Gakratr

\section{BRITISH NON-FERROUS METALS RESEARCH ASSOCIATION OPEN DAYS}

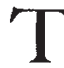

HE British Non-Ferrous Metals Research Association is this year celebrating the twenty-fifth anniversary of the opening of its own laboratory premises at Euston Street in London. The occasion was marked by a visit from H.R.H. the Duke of Edinburgh on May 23, and for the remainder of the week the laboratories were open to the representatives of member firms, government departments and others.

The original laboratory block in Euston Street was almost completely destroyed by enemy action during the Second World War; but it has since been rebuilt and now houses most of the Association's general metallurgy work and its metal-working plant. The laboratories have, however, been expanded considerably into adjacent blocks of buildings and now cover a floor area of about $43,000 \mathrm{sq}$. ft. and house a staff of about a hundred and fifty. The exhibition of work in connexion with these open days covered a very wide range of subjects, and in this short note it is only possible to refer to a few of those having a more purely scientific appeal.

For some years now the Association has been investigating the causes of the pitting corrosion of copper water-pipes which occurs in certain localities in Great Britain. Pitting corrosion is comparatively rare and usually affects only a few installations in any particular area. It has been found to be associated with cathodic films occurring under certain circum. stances in the bore of copper pipes. The fact that pitting corrosion is rare is probably due to the presence of a natural inhibitor in many supply waters, and a great deal of work has gone into the separation of this inhibitor and in attempts to identify it. 